\title{
Persepsi Politik Masyarakat Dalam Pembentukan Daerah Otonomi Baru Wasile Raya Di Kabupaten Halmahera Timur: Studi Desa Loleba Kecamatan Wasile Selatan
}

\author{
${ }^{1}$ Abdulhalil Hi. Ibrahim, ${ }^{2}$ Bakri La Suhu, ${ }^{3}$ Syaiful Madjid, ${ }^{3}$ Rulex Sonotox, ${ }^{4}$ Marno \\ Wance \\ ${ }^{1234}$ Fakultas Ilmu Sosial dan Ilmu Politik, Universitas Muhammadiyah Maluku Utara, \\ Indonesia \\ ${ }^{5}$ Fakultas Ilmu Sosial dan Ilmu Politik, Universitas Pattimura, Indonesia
}

\begin{abstract}
ABSTRAK
Penelitian ini bertujuan untuk mengetahui permasalahan mengenai dengan persepsi politik masyarakat dalam pembentukan daerah otonomi baru di Desa Loleba Kecamatan Wasile Selatan Kabupaten Halmahera Timur. Metode yang digunakan dalam penelitian ini adalah deskriptif kualitatif, metode ini digunakan dengan maksud membuat penggambaran secara sistimatis, factual, dan akurat dalam menganalisis fakta-fakta secara langsung dilapangan. Hasil temuan penelitian menunjukkan bahwa persepsi politik masyarakat dalam pembentukan daerah otonomi baru (DOB) tahun 2014 tidak berjalan sesuai dengan keinginan masyarakat, padahal awal tahun 2014 isu pemekaran sangatlah direspon baik oleh seluruh lapisan masyarakat Desa Loleba sehingga masyarakat tidak segan-segan dalam memberikan dukungan mereka. Persepsi ini muncul karena, pertama rentang jarak yang cukup jauh dari ibukota kabupaten induk dengan Kecamatan Wasile Selatan. Kedua, pemikiran politik ini lahir karena dalam proses pengurusan administrasi misalnya KTP, KK, Akta Kelahiran, seringkali terkendala pada biaya transportasi yang terlalu tinggi. Alasan inilah yang mendorong semangat masyarakat tetap mendukung agenda rencana pemekaran Wasile Raya menjjadi kabupaten yang baru.
\end{abstract}

Kata Kunci: Persepsi, Politik Masyarakat dan Pemekaran Daerah

\section{PENDAHULUAN}

Pembentukkan daerah otonom baru (pemekaran daerah) merupakan isu menarik yang selalu diperbincangkan baik di media massa, elektronik, maupun media cetak. Isu ini mendapat perhatian banyak kalangan, mulai dari akademisi, praktisi hingga politisi. Sejak bergulirnya reformasi 1998 hingga saat ini, tuntutan pemekaran daerah di Indonesia terus saja berlangsung dari tahun ke tahun bahkan mengalami peningkatan. (Rahmat Suaib, 2020)

Menurut Peraturan Pemerintah Nomor 129 Tahun 2000 bahwa tujuan pemekaran daerah senantiasa diarahkan untuk meningkatkan kesejahteraan masyarakat melalui: 1) peningkatan pelayanan kepada masyarakat; 2) percepatan pertumbuhan kehidupan masyarakat; 3) percepatan pelaksanaan pembangunan perekonomian daerah; 4) percepatan pengelolaan potensi daerah; 5) peningkatan keamanan dan ketertiban; dan 6) peningkatan hubungan yang serasi antara pusat dan daerah. Untuk itu, pembentukan daerah harus mempertimbangkan berbagai faktor 
seperti kemampuan ekonomi, potensi daerah, luas wilayah, kependudukan, dan pertimbangan dari aspek sosial politik, sosial budaya, pertahanan dan keamanan serta pertimbangan dan syarat lain yang memungkinkan daerah itu dapat menyelenggarakan dan mewujudkan tujuan dibentuknya daerah dan diberikannya otonomi daerah. (Bakri La Suhu, et al, 2018)

Maluku Utara merupakan salah satu provinsi kepulauan, sehingga banyak daerah menuntut adanya pemekaran wilayah. Di bagian Selatan Halmahera, masyarakat Pulau Obi sudah menggagas dan mendeklarasikan kabupaten kepuluan Obi sejak 2008, (Bakri La Suhu, et al, 2011). Ujung Utara Halmahera yakni GalelaLoloda (GALDA) juga menyuarakan pemekaran daerah. (Abdulhalil Hi. Ibrahim, dkk, 2020), sedangkan untuk wilayah Kota Tidore Kepulauan, ada tuntutan untuk pembentukan Otonomi Khusus yang disuarakan masyarakat dan beberapa kalangan elite. (Nardiansyah Noor, dkk, 2018).

Pada bagian Timur Halmahera ada Wasile. Wasile Raya adalah salah satu daerah yang berada di Provinsi Maluku Utara bagian timur juga bagian dari Kabupaten Halmahera Timur yang lagi marak menuntut agar secepatnya terlepas dari kabupaten induk dan menjadi satu daerah yang mandiri atau yang dapat disingkat dengan DOB. Hanya saja sampai saat ini harapan untuk menjadi satu kabupatn baru tidak terealisasi, padahal isu pemekaran sudah sejak tahun 2013 sampai tahun 2014 berkembang di kalangan masyarakat Desa Loleba. Keinginan masyarakat untuk melepaskan diri dari kabupaten induk dan menjadi kabupaten baru, hanya menjadi isu politik yang dipolitisasi oleh elit politik dalam meraut kepentingan pribadi atau kelompoknya.

Kondisi ini sangat memilukan dari hari ke hari, harapan dan cita-cita selalu membayang dalam pikiran dan sanubari masyarakat Desa Loleba bawahsanya Wasile Raya akan terlepas dari Ibukota Maba dan menjadi daerah otonom baru. Namun pada kenyataannya wacana pemekaran kini jauh dari harapan dan kenyataan yang sesungguhnya. Sementara, masyarakat Desa Loleba sangat menantikan Pemekaran Wasile Raya dapat berjalan secara sinergis. Mengingat bahwa satu daerah bisa terlaksana menjadi daerah otonomi baru tergantung pada semangat dan dukungan masyarakat dalam mendorong proses pembentukan daerah otonomi baru sebagai wujud pelaksanaan kedaulatan rakyat ditingkat daerah. Oleh karena itu, keterlibatan masyarakat sangat dibutuhkan dalam suatu daerah yang berkeinginan melepaskan dari kabupaten induk dan membentuk kabupaten baru.

Jikalau mengacu secara administratif, teknis dan fisik, Wasile Raya sudah layak menjadi satu kabupaten baru, hanya saja pemerintah Kabupaten Halmahera Timur tidak jelih dalam mengawal dan mendorong proses pembentukan Wasile Raya sebagai kabupaten baru, ini menunjukkan kelalaian pemerintah Kabupaten Halmahera Timur dalam mendorong Wasile Raya menjadi daerah yang mandiri. Argumentasi pemerintah daerah beralasan bahwa terhambatnya pembentukan kabupaten baru (Wasile Raya) karena adanya perancangan UU Pemilihan Kepala Daerah Serentak di tahun 2015-2016, juga pemerintah daerah lagi sibuk dalam 
menyabut pesta demokrasi.

Problem tersebut inilah, yang mengakibatkan terhambatnya proses pembentukan pemekaran Wasile Raya sebagai kabupaten baru. Alasan seperti ini bisa saja mendapat memunculkan rasa curiga dari masyarakat Desa Loleba terhadap pemerintah Induk Kabupaten Halmahera Timur, yang sengaja menjadikan isu pemekaran daerah menjadi senjata politik dalam momen pemilihan kepala daerah (Pilkada) tahun 2016 sebagai jalan melanganggengkan kepentingan pribadi.

\section{KAJIAN PUSTAKA}

\section{Dimensi Normatif Pemekaran Daerah}

Gagasan pemekaran wilayah dan pembentukan daerah otonom baru memiliki dasar hukum yang cukup kuat. Secara yuridis landasan yang memuat persoalan pembentukan daerah terdapat dalam pasal 18 Undang-undang Dasar (UUD) 1945 yang berbunyi : "Pembagian daerah Indonesia atas daerah besar dan kecil, dengan bentuk susunan pemerintahannya ditetapkan dengan Undang-undang, dengan memandang dan mengingati dasar permusyawaratan dalam sistem pemerintahan negara, dan hak-hak asal-usul dalam daerah yang bersifat istimewa (Hanif Nurcholis, 2005).

Pembentukan daerah adalah pemberian status pada wilayah tertentu sebagai daerah provinsi atau daerah kabupaten/kota, sedangkan pemekaran daerah adalah pemecahan provinsi atau kabupaten/kota menjadi dua daerah atau lebih (Peraturan Pemerintah Nomor 78 Tahun 2007). Konsekuensi dari pemekaran daerah secara praktis akan terjadi perubahan struktur organisasi pemerintahan, perubahan luas wilayah yang diikuti perubahan batas-batas wilayah dan perubahan jumlah penduduk. Perubahan ini akan berimplikas terhadap perubahan-perubahan lain lebih esensial, khususnya dalam upaya pemberian pelayanan kepada masyarakat. (Darmawan, 2008).

Pada dasarnya usaha pemekaran suatu daerah menjadi dua atau lebih tidak dilarang, asalkan didukung oleh keinginan sebagian besar masyarakat dan memenuhi persyaratan administratif, teknis, dan fisik wilayah. Selain itu, berdasarkan Undang-undang Nomor 32 Tahun 2004 diganti dengan UU No. 23 tahun 2014 tentang Pemerintah Daerah, pembentukan daerah pada dasarnya bertujuan untuk meningkatkan pelayanan publik guna mempercepat terwujudnya kesejahteraan masyarakat.

\section{Syarat Pembentukan Daerah Otonom Baru}

Persyaratan Pembentukan Daerah Otonom Baru (DOB), secara normatif telah diatur dalam Peratura Pemerintah (PP) Nomor 78 Tahun 2007 Tentang Tata Cara Pembentukan, Penghapusan, dan Penggabungan Daerah yang meliputi syarat administratif, teknis, dan fisik kewilayahan. Persyaratan administratif pembentukan daerah kabupaten/kota meliputi: 
1. Keputusan Dewan Perwakilan Rakyat Daerah (DPRD) kabupaten/kota induk tentang persetujuan pembentukan calon kabupaten/kota;

2. Keputusan bupati/walikota induk tentang persetujuan pembentukan calon kabupaten/kota;

3. Keputusan Dewan Perwakilan Rakyat Daerah (DPRD) provinsi tentang persetujuan pembentukan calon kabupaten/kota;

4. Keputusan gubernur tentang persetujuan pembentukan calon kabupaten/kota; dan

5. Rekomendasi Menteri.

Keputusan DPRD kabupaten/kota diproses berdasarkan aspirasi sebagian besar masyarakat setempat. Dan keputusan DPRD provinsi berdasarkan aspirasi sebagian besar masyarakat setempat yang dituangkan dalam keputusan DPRD kabupaten/kota yang akan menjadi cakupan wilayah calon provinsi.

Persyaratan secara teknis didasarkan pada faktor kemampuan ekonomi, potensi daerah, sosial budaya, sosial politik, kependudukan, luas daerah, pertahanan, keamanan, dan faktor lain yang memungkinkan terselenggaranya otonomi daerah. Adapun faktor lain tersebut meliputi pertimbangan kemampuan keuangan, tingkat kesejahteraan masyarakat, dan rentang kendali penyelenggaraan pemerintahan. Faktor sebagaimana dimaksud, dinilai berdasarkan hasil kajian daerah terhadap indikator sebagaimana tercantum dalam lampiran yang merupakan bagian yang tidak terpisahkan dari Peraturan Pemerintah ini. Suatu calon daerah otonom direkomendasikan menjadi daerah otonom baru apabila calon daerah otonom dan daerah induknya mempunyai total nilai seluruh indikator dan perolehan nilai indikator faktor kependudukan, faktor kemampuan ekonomi, faktor potensi daerah dan faktor kemampuan keuangan dengan kategori sangat mampu atau mampu.

Syarat fisik kewilayahan meliputi cakupan wilayah, lokasi calon ibukota, sarana dan prasarana pemerintahan. Cakupan wilayah untuk: pembentukan provinsi paling sedikit 5 (lima) kabupaten/kota; kabupaten paling sedikit 5 (lima) kecamatan; dan kota paling sedikit 4 (empat) kecamatan.

Dengan persyaratan dimaksud diharapkan agar daerah yang baru dibentuk dapat tumbuh, berkembang dan mampu menyelenggarakan otonomi daerah dalam rangka meningkatkan pelayanan publik yang optimal guna mempercepat terwujudnya kesejahteraan masyarakat dan dalam memperkokoh keutuhan Negara Kesatuan Republik Indonesia. Dalam pembentukan daerah, tidak boleh mengakibatkan daerah induk menjadi tidak mampu menyelenggarakan otonomi daerah, sehingga tujuan pembentukan daerah dapat terwujud dengan dilengkapi dengan kajian daerah.

\section{METODE PENELITIAN}


Tipe dan jenis penelitian digunakan adalah deskriptif kualitatif yakni serangkaian prosedur yang digunakan dalam pemecahan yang diselidiki/diteliti dengan menggambarkan keadaan objek-objek penelitian. Penelitian deskriptif berupa katakata tertulis atau lisan dari orang-orang dan perilaku yang dapat diamati. Yang diarahkan untuk menjelaskan hal-hal atau masalah yang terjadi dan gambaran sesuai dengan fokus masalah penelitian (Lexy J. Moleong, 2001).

\section{HASIL DAN PEMBAHASAN}

\section{Isu Pemekaran Wasile Raya Jadi Perhatian Masyarakat}

Begitu lajunya transisi waktu dari hari kehari memasuki tahun 2014, ada kelompokkelompok mahasiswa yang menggelar gerakan demonstrasi untuk meminta sikap masyarakat dalam mendorong pemekaran daerah Wasile Raya yang sudah dijanjikan oleh pemerintah Kabupaten Halmahera Timur. Kelompok mahasiswa ini, kemudian memberikan pencerahan kepada masyarakat apa sebenarnya makna yang dikandung oleh otonomi daerah, dari sinilah lahir kesadaran masyarakat untuk berpartisipasi dan bergabung bersama gerakan mahasiswa yang mengatasnamakan gerakan muda peduli rakyat.

Isu pemekaran menjadi perhatian penuh di tahun 2014, masyarakat sangat gencar mewacanakan isu pemekaran, semangat ini memicu dan ditunjang oleh sebah cita-cita serta harapan untuk mekar, sehingga masyarakat tidak pernah merasa jenuh dan bosan dalam rangka mendukung apa yang sudah diprogramkan oleh pemerintah daerah Kabupaten Halmahera Timur untuk memekarkan Wasile Raya menjadi daerah otonom baru. Semangat selalu bertebaran dimana-mana, menggambarkan ada sebuah kerinduan serta harapan masyarakat agar pemerintah dapat merealisasikan keinginan masyarakat untuk mandiri menjadi kabupaten baru.

Getiran dan semangat terus bergulir mengikuti alur putaran jam dan sampailah di tahun 2015, isu pemekaran masih menjadi tema sentral dalam pendiskusian masyarakat, karena tahun 2015 bertepatan dengan proses pelaksaanaan pemilihan kepala daerah sehingga Rudi Erawan lebih pandai memainkan isu tersebut yang tujuannya menyakinkan kepada masyarakat agar kepentingannya dapat berjalan dengan baik.

Namun, ironisnya memasuki tahun 2016 dan 2017 ternyata ada rasa kekecewaan yang muncul dalam tatanan masyarakat sehingga isu pemekaran tidak lagi terdengar dibibir masyarakat, bahkan ketika ditanya tentang pemekaran Wasile Raya tidak lagi menimbulkan gairah dalam masyarakat. Ini dapat dicermati, kalaupun dapat dibandingkan isu pemekaran di tahun 2014 lebih besar mendapat dukungan ketimbang di tahun 2017, isu pemekaran tersebut kemudian tenggelam mengikuti arus waktu.

Proses waktu terus berjalan begitu cepat mengikuti putaran jam dan telah membawa masyarakat di tahun 2017. Isu pemekaran tidak lagi terdengar ditelinga 
masyarakat Halmahera Timur dan khususnya masyarakat Loleba. Masa-masa tahun 2017 adalah sebuah masa yang dimana masyarakat tidak lagi percaya terhadap pemerintah daerah Kabupaten Halmahera Timur, krisis kepercayaan melanda di masyarakat pada penghujung tahun 2017 sehingga isu pemekaran Wasile Raya tidak lagi menjadi tema diskusi di kalangan masyarakat Halmahera Timur dan khususnya Desa Loleba.

Pemekaran Wasile Raya sudah cukup lama dan membutuhkan waktu yang sangat panjang mulai dari tahun 2009, 2014 sampai 2017, tapi dalam proses realisasinya terkesan tidak berjalan sesuai dengan mekanisme yang telah diatur. Memang ada sebuah upaya dari pemerintah untuk mendorong Wasile Raya sebagai kabupaten baru, namun mengalami kendala pada agenda momentum pemilihan kepala daerah yang menyebabkan terhambatnya pelaksanaan pemekaran daerah Wasile Raya. Alasan ini, tidak memunculkan rasa simpati masyarakat dan justru masyarakat beranggapan alasan tersebut adalah sarat akan kebohongan, sehingga memunculkan rasa justifikasi dari masyarakat bahwa pemerintah daerah Kabupaten Halmahera Timur tidak sungguh-sungguh dalam memperjuangkan Wasile Raya sebagai daerah otonomi baru.

\section{Persepsi Politik Masyarakat Desa Loleba}

Wacana pemekaran berkembang pada tatanan kehidupan masyarakat bukan lagi hal baru, namun hal itu sudah cukup lama dan membutuhkan waktu yang sangat panjang. Dalam proses perjalanannya isu pemekaran daerah Wasile Raya pertama kali dikampanyekan pada tahun 2009 ketika Rudi Erawan menjadi peserta kontestan dalam saibara pemilihan kepala daerah Kabupaten Halmahera Timur. Isu pemekaran yang disuarakan Rudi Erawan kemudian dijadikan angin segar dan janji politik bagi masyarakat. Namun setelah Rudi Erawan terpilih, isu pemekaran Wasile Raya tidak terealisasi sesuai dengan janji yang telah disampaikan sebelumnya.

Isu pemekaran tahun 2014 lalu pada kenyataannya masyarakat benar-benar sangat merindukan agar apa yang telah dijanjikan oleh pemerintah daerah tentang pemekaran Wasile Raya dapatlah berjalan sebagaimana mestinya. Pertanyaan demi pertanyaan kapan Wasile Raya dimekarkan, menjadi suatu tanda tanya bagi masyarakat Desa Loleba yang menginginkan adanya pemekaran Wasile Raya.

Bagi masyarakat Desa Loleba sangat mendukung agenda pemekaran daerah otonomi baru Wasile Raya. Keinginan ini memiu dilatarbelakangi dengan sebuah harapan masyarakat Desa Loleba benar-benar mengharapkan agar rencana pemekaran Wasile Raya dapat berjalan sesuai dengan keinginan dan cita-cita masyarakat setempat, hanya saja isu pemekaran sampai sejauh ini belum terbukti, padahal isu pemekaran mendapat respon serta dukungan yang baik dari seluruh lapisan masyarakat Desa Loleba.

\section{Gagasan Politik Masyarakat}

Konsep persepsi masyarakat sangatlah penting dalam mendukung proses 
pembentukan otonomi daerah (DOB) untuk suatu daerah. Untuk masyarakat Loleba, tanggapan akan isu pemekaran daerah sangatlah tinggi ketika mendengar Wasile Raya akan menjadi daerah mandiri yang berotonom. Hal ini dapat dilihat dari sisi dukungan masif yang diberikan oleh masyarakat oleh masyarakat lewat sumbangsi pemikiran dan fisik pada waktu melakukan gerakan demonstrasi dengan kelompok mahasiswa yang menuntut pemekaran Wasile Raya. Demonstrasi itu dilaksanakan di Kantor Camat Wasile Selatan dan Kantor Camat Kecamatan Induk.

Memang masyarakat Desa Loleba belum optimal dalam memberikan sumbangsi pemikiran politik ketika mendorong Wasile Raya menjadi daerah kabupaten baru. Namun inilah cara dimana masyarakat menunjukan rasa kerinduan untuk melepaskan diri dari kabupaten induk dan menjadi rumah tangga sendiri. Rasa ketertarikatan dan keinginan yang tinggi dari masyarakat untuk mendorong pemekaran Wasile Raya sehingga masyarakat Desa Loleba memiliki niat politik untuk ambil bagian mengikuti demonstrasi menuntut adanya pemekaran Wasile Raya.

Semangat dan respon positif dari masyarakat menginginkan pemekaran daerah otonomi baru (DOB) Wasile Raya sangat diharapkan, sehingga isu pemekaran menjadi isu sensitif dikalangan masyarakat Desa Loleba. Berbagai harapan masyarakat agar pemekaran Wasile Raya menjadi kenyataan sangat dinantikan hingga sekarang.

\section{Alasan Masyarakat Loleba untuk Mekar}

Ada beberapa faktor lain yang mendorong munculnya persepsi politik masyarakat dalam merespon pembentukan otonomi baru, pertama karena faktor administrasi. Hal ini dapat dilihat ketika masyarakat melakukan pengurusan (KTP, KK, Akta Kelahiran, dll) seringkali mengalami kendala, persoalannya adalah letak kedudukan kabupaten induk dengan daerah kecamatan sangatlah jauh sehingga membutuhkan biaya transportasi yang cukup besar, faktor administrasi tersebut telah mempengaruhi persepsi seluruh lapisan sehingga semangat untuk mendorong pemekaran itupun lahir dari hati nurani rakyat. Faktor kedua adalah teritorial, faktor ini dapat dilihat dari rentang jarak yang sangat jauh antara ibukota kabupaten dengan daerah-dearah kecamatan lain, sehingga dapat menghambat aksesbilitas masyarakat dalam memperjuangkan kepentingan masyarakat.

Keinginan untuk mekar adalah sebuah alasan yang tepat bagi seluruh lapisan masyarakat, mengingat otonomi daerah dapatlah menciptakan sebuah tatanan kehidupan masyarakat yang lebih baik kedepannya. Namun keinginan tersebut belum kesampaian dan belum menjadi kenyataan, ini dikarenakan ada sebuah praktek terselubung yang dilakukan oleh Pemerintah daerah Kabupaten Halmahera Timur yang terkesan menjadikan isu pemekaran sebagai senjata politik dalam meraut kepentingan privasinya, menjadi penguasa di Kabupaten Halmahera Timur. Pemekaran Wasile Raya tinggal menjadi isu belaka, yang tak kunjung datang.

\section{KESIMPULAN DAN SARAN}




\section{Kesimpulan}

1. Masyarakat Desa Loleba sangat mendukung pemekaran Wasile Raya, hanya saja pemekaran ini belum berjalan baik sesuai dengan cita-cita dan keinginan masyarakat setempat. Masyarakat Loleba begitu antusias merespon ketika mendengar Wasile Raya akan menjadi DOB, berbagai persepsi dan dukungan masyarakat Loleba telah disampaikan melalui aksi demonstrasi bersama kelompok mahasiswa.

2. Harapan masyarakat lambat dan cepat, pemerintah daerah harus dapat memastikan janji-janji manis untuk membuktikan Wasile Raya harus dimekarkan, terlepas dari kabupaten induk. Sampai sekarang, masyarakat masih menantikan kepastian pemekaran Wasile Raya walaupun isu pemekaran tidak lagi diwacanakan di kalangan masyarakat Desa Loleba. Akan tetapi, harapan masyarakat tidka pernah usai menantikan Wasile Raya sebagai kabupaten baru.

\section{Saran}

1. Masyarakat jangan terlalu cepat percaya dengan kobaran-kobaran janji yang disampaikan oleh pemerintah. Patut untuk disaring sebaik mungkin agar tidak terperangkap dengan janji-janji palsu yang telah dimanipulasi oleh pimpinan daerah.

2. Pemekaran daerah haruslah dapat mengacu pada kepentingan masyarakat, jangan hanya membuka kepentingan-kepentingan para elit-elit lokal yang lebih gencar meraut kemewahan. Oleh karena itu, sebagai tawaran apabila dikemudian hari daerah Wasile Raya dimekarkan, pastikanlah bahwa masyarakat memiliki aksesbilitas dan akuntabilitas yang dijadikan sebagai program prioritas pelayanan publik yang optimal kepada masyarakat.

\section{DAFTAR PUSTAKA}

B LA SUHU, S IP, MA Abdul Gaffar Karim - 2011, PEMEKARAN DAERAH: PROKONTRA DAN KONSPIRASI (Studi Tentang Konfigurasi Elit dalam Pemekaran Kabupaten Kepulauan Obi Halmahera Selatan-Maluku Utara), Universitas Gadjah Mada

Darmawan, dkk. Studi Evaluasi Dampak Pemekaran Daerah 2001-2007, 2008, Bridge Bappenas.

IBRAHIM, Abdul Halil; LA SUHU, Bakri; WANCE, Marno. PERAN DEWAN PERWAKILAN DAERAH (DPD) DALAM PEMBENTUKAN DAERAH OTONOMI BARU (DOB) DI WILAYAH PROVINSI MALUKU UTARA. Nakhoda: Jurnal Ilmu Pemerintahan, 19.1.

LA SUHU, Bakri; NOOR, Nardiansyah; DJAE, Raoda M. BATAS DAERAH DALAM PUSARAN KONFLIK DI PROVINSI MALUKU UTARA (Studi Tentang 
Penyelesaian Sengketa Tapal Batas Antara Kabupaten Halmahera Timur Dan Kabupaten Halmahera Tengah). Ejournal KAWASA, 2018, 8.4: 1-11.

Lexy, J. Moleong. 2001. Metode Penelitian Kualitatif. Bandung: Remaja Rosdakarya

NOOR, Nardiansyah; LATING, Ali; SUAIB, Rahmat. OTONOMI KHUSUS ANTARA HARAPAN DAN KENYATAAN (Studi Political Will Pemerintah Kota Tidore Dalam Mendorong Pembentukan Otonomi Khusus Tidore Kepulauan). Ejournal KAWASA, 2018, 8.4: 12-23.

Nurcholis, Hanif 2005. Teori dan Praktek Pemerintahan Dan Otonomi Daerah. Penerbit PT. Gramedia Widiasarana Indonesia, Jakarta.

SUAIB, Rahmad. URGENSI PEMEKARAN DAERAH DI INDONESIA. JURNAL GOVERNMENT OF ARCHIPELAGO-JGOA, 2020, 1.1: 34-44.

Undang-Undang Nomor 32 Tahun 2004 Tentang Pemerintahan Daerah dan penggantinya yaitu Undang-undang Nomor 23 Tahun 2014 tentang Pemerintahan Daerah

Peraturan Pemerintah No. 78 Tahun 2007 tentang Tata Cara Pembentukan, Penghapusan, dan Penggabungan Daerah 